\title{
Canadians' perception of food allergy risk
}

\author{
Daniel W Harrington ${ }^{1 *}$, Susan J Elliott ${ }^{1}$, Moshe Ben-Shoshan², Samuel Godefroy ${ }^{4}$, Joseph Fragapane ${ }^{3}$, \\ Lianne Soller ${ }^{3}$, Marilyn Allen ${ }^{5}$, Mary Allen ${ }^{6}$, Claire Dufresne ${ }^{7}$, Laurie Harada ${ }^{5}$, Ann E Clarke ${ }^{8}$ \\ From AllerGen NCE Inc.'s Fifth Annual Research Conference: Innovation from Cell to Society \\ Québec City, QC, Canada. 7-9 February 2010
}

\section{Objective}

The purpose of this research is to explore the determinants of the perceived risks associated with food allergy and anaphylaxis.

\section{Methods}

Households $(\mathrm{n}=3,666)$ were selected at random, as part of a national food allergy prevalence survey, and data were collected via telephone. In addition to determining household allergy status, respondents were asked about environmental health risks, including those associated with food allergy/anaphylaxis. Multivariate logistic regressions, weighted to the age-sex structure of the Canadian population, were used to determine the characteristics of respondents who ranked the risks of food allergy and anaphylaxis as 'High' or 'Moderate'.

\section{Findings}

One-fifth of the sample reported having at least one food allergy in the household. Almost 70\% of respondents ranked the risks of food allergy as high or moderate risks, compared to just over $60 \%$ for anaphylaxis. Determinants include well-established demographic predictors of health risks perceptions (e.g., age, gender). Other important covariates suggest that general attitudes towards environmental health risks in general, knowledge about foood allergies, and worldviews are significant predictors of food allergy and anaphylaxis risk. In terms of risk experience, only respondents with multiple food allergies in the household significantly ranked the perceived risks as high or moderate (OR: 2.77, 95\% CI: $[1.56,5.27])$. Broad regional differences in risk perception were observed in this survey. Respondents from Quebec resported a greater degree of perceived societal

${ }^{1}$ School of Geography and Earth Sciences, McMaster University, Hamilton, Ontario, L8S 4L8, Canada

Full list of author information is available at the end of the article risk for food allergy (OR: 2.07, 95\%CI: [1.63, 2.63]) and anaphylaxis (OR: 1.34, 95\%CI: [1.08, 1.67]).

\section{Conclusions}

Studies of risk perception have established the importance of understanding risk perceptions for explaining how the public responds to risk. In the context of food allergy, and anaphylactic food allergy, there is a need to develop appropriate policy responses that can protect allergic individuals, while accommodating the general population. This research contributes to this need by characterizing the societal response to the prevalence of food allergies and anaphylactic food allergies. Analyses revealed marked differences between Quebec and other provinces. It is becoming increasingly apparent that the policy environment in this province in particular is a key determinant of the experience and perception of allergy-related risk. Results from this research indicate that both the perceptions of affected and unaffected populations are modified in this context. Policymakers need to consider these impacts as advancements in regulations and policy emerge in this area.

\section{Author details \\ ${ }^{1}$ School of Geography and Earth Sciences, McMaster University, Hamilton, Ontario, L8S 4L8, Canada. ${ }^{2}$ Division of Pediatric Allergy and Clinical Immunology, Department of Pediatrics, McGill University Health Centre, Montreal, Quebec, H3H 1P3, Canada. ${ }^{3}$ McGill University Health Centre, Montreal, Quebec, H3H 1P3, Canada. ${ }^{4}$ Health Canada, Ottawa, Ontario, K1A OK9, Canada. ${ }^{5}$ Anaphylaxis Canada, Toronto, Ontario, M2J 5B4, Canada. ${ }^{6}$ Allergy/Asthma Information Association, Vaughn, Ontario, $\mathrm{L} 4 \mathrm{H} 3 \mathrm{H} 9$, Canada. ${ }^{7}$ Association Quebecoise des Allergies Alimentaires, Montreal, Quebec, H1S 3B1, Canada. ${ }^{8}$ Divisions of Allergy and Clinical Immunology and Clinical Epidemiology, Department of Medicine, McGill University Health Centre, Montreal, Quebec, H3H 1P3, Canada.}

Published: 26 November 2010

doi:10.1186/1710-1492-6-S3-P31

Cite this article as: Harrington et al:: Canadians' perception of food allergy risk. Allergy, Asthma \& Clinical Immunology 2010 6(Suppl 3):P31. 